\title{
Hydroxychloroquine use is not associated with QTc length in a large cohort of SLE and RA patients
}

\author{
Elizabeth Park ${ }^{1 *}{ }^{\mathbb{D}}$, Jon T. Giles ${ }^{1}$, Thania Perez-Recio ${ }^{1}$, Paloma Pina ${ }^{2}$, Christopher Depender ${ }^{1}$, \\ Yevgeniya Gartshteyn ${ }^{1}$, Anca D. Askanase ${ }^{1}$, Joan Bathon ${ }^{1}$ and Laura Geraldino-Pardilla ${ }^{1}$
}

\begin{abstract}
Background: Hydroxychloroquine (HCQ) is a cornerstone therapy for systemic lupus erythematosus (SLE) and rheumatoid arthritis (RA). However, reports of its use and subsequent fatal arrhythmias in patients with coronavirus disease 19 (COVID-19) have raised concern regarding its cardiovascular (CV) safety. Therefore, we examined the relationship between HCQ use and corrected QT (QTc) length in SLE and RA patients without clinical CV disease (CVD).

Methods: SLE patients from the Columbia University Lupus Cohort registry $(n=352)$ and two RA cohorts $(n=178$; ESCAPE-RA and RHYTHM-RA) with electrocardiograms (ECGs) collected as part of study data were analyzed. RA cohort participants were recruited from tertiary referral centers with additional referrals from community rheumatologists, while SLE subjects originated from the Columbia University Lupus Cohort. All patients met American College of Rheumatology (ACR) classification criteria for SLE or RA and lacked known CVD. The exposure of interest was HCQ use and main outcome measure was QTc length [continuous or categorical ( $\geq 440 \mathrm{~ms}$ and $\geq 500 \mathrm{~ms}$ )].
\end{abstract}

Results: Of the combined SLE and RA cohorts $(n=530), 70 \%$ were HCQ users and $44 \%$ had a QTc $\geq 440 \mathrm{~ms}$. The adjusted mean QTc length was comparable between HCQ users vs non-users (438 ms vs $437 \mathrm{~ms}$ ). In multivariable logistic models, HCQ use was not a significant predictor of a QTc $\geq 440 \mathrm{~ms}$ for the entire cohort (OR $0.77 ; 95 \% \mathrm{Cl}$ $0.48-1.23 ; p=0.27$ ). Importantly, a QTc $\geq 500 \mathrm{~ms}$ was inversely associated with HCQ use and not associated with arrhythmias or deaths. A significant interaction was found between HCQ use and use of anti-psychotics. Ultimately, the use of HCQ combined with any QTc prolonging medication as a group was associated with a QTc length (434 ms; $95 \% \mathrm{Cl} 430,439)$ which was comparable to that of use of HCQ alone (433 ms; 95\% Cl 429-437).

Conclusion: In a combined cohort of SLE and RA patients without clinical CVD, adjusted QTc length was comparable between HCQ and non-HCQ users, supporting its CV safety in patients with rheumatic diseases.

Keywords: Rheumatoid arthritis, Systemic lupus erythematosus, Hydroxychloroquine, QTC

\footnotetext{
*Correspondence: ep2899@cumc.columbia.edu

${ }^{1}$ Division of Rheumatology, Columbia University Vagelos College

of Physicians and Surgeons and New York Presbyterian Hospital, 630 W 168th St, P\&S 3-450, New York, NY 10032, USA

Full list of author information is available at the end of the article
}

\section{Background}

Hydroxychloroquine (HCQ) has long been a cornerstone therapy for systemic lupus erythematosus (SLE) and is commonly used as monotherapy or combined with other disease modifying anti-rheumatic drugs (DMARDs) for rheumatoid arthritis (RA). HCQ neutralizes acidic cytoplasmic components within the lysosome, leading to downstream alterations in antigen processing and original author(s) and the source, provide a link to the Creative Commons licence, and indicate if changes were made. The images or other third party material in this article are included in the article's Creative Commons licence, unless indicated otherwise in a credit line to the material. If material is not included in the article's Creative Commons licence and your intended use is not permitted by statutory regulation or exceeds the permitted use, you will need to obtain permission directly from the copyright holder. To view a copy of this licence, visit http://creativecommons.org/licenses/by/4.0/. The Creative Commons Public Domain Dedication waiver (http://creativeco mmons.org/publicdomain/zero/1.0/) applies to the data made available in this article, unless otherwise stated in a credit line to the data. 
inhibition of toll-like receptors [1,2]. The observed cutaneous, retinal, and musculoskeletal toxicities are thought to arise from long-term storage of its metabolite, 4-aminoquinolone, in these tissues [2].

Acute cardiovascular (CV) toxicities from short-term exposure of HCQ (and subsequent blocking of potassium channels within myocytes) manifest as QT interval prolongation, and when combined with additional baseline risk factors, such as age, sex, high levels of anti-Ro antibodies [3], and arrhythmogenic congenital long QT syndromes [4], acute arrhythmic events (i.e., torsades de pointes) also occur [5]. With long-term exposure, HCQ metabolites may also accumulate in the myocardium and result in a cardiomyopathy with concentric hypertrophy and conduction abnormalities $[1,5,6]$. In fact, 33 of 42 histologically confirmed cases of HCQ induced cardiomyopathy originated from RA and SLE patients, who on average had been on treatment for 13 years [1]. Moreover, 14 of those 42 cases progressed to third-degree atrioventricular block. However, there are no current guidelinebased recommendations for $\mathrm{CV}$ screening in the setting of prolonged HCQ use.

Recent reports $[7,8]$ of possible associations between concurrent HCQ and azithromycin use and QTc prolongation in those receiving treatment for coronavirus disease 2019 (COVID-19)-associated pneumonia have raised further concerns for HCQ-associated cardiotoxicity. However, the wide spectrum of cardiotoxic effects of COVID-19 itself (arrhythmias, myocarditis, microvascular injury, stress cardiomyopathy) [9] confound these observations. In observational (mostly retrospective) studies in rheumatic disease patients [10-14], there were no differences in QTc prolongation in HCQ users vs nonusers, nor was there an association between QTc length and HCQ use, keeping in mind that these studies did not consistently account for the use of other prolonging QTc medications. We therefore investigated associations between HCQ use and QTc length in an SLE and RA cohort without known CV disease (CVD), accounting for the use of various QTc prolonging medications.

\section{Methods}

\section{Study population}

A total of 530 SLE and RA patients on whom HCQ use information was available were included in the study.

\section{SLE patients}

With approval from the Columbia University Institutional Review Board, electronic clinical data from the Columbia University Lupus Cohort registry was retrospectively reviewed. The patients consisted of all inpatients and outpatients seen at the Columbia University Irving Medical Center (CUIMC)/New York Presbyterian
Hospitals (NYPH) with an SLE or lupus nephritis diagnosis attested by the International Classification of Diseases, Ninth and Tenth Revision, Clinical Modification (ICD-9/ICD-10) billing code diagnosis, between January 2015 and December 2019. Inclusion criteria were as follows: 1) $\geq 2$ SLE ICD-9/ICD-10 billing diagnoses confirmed by manual chart review (fulfilling at least 4 ACR classification criteria [15]) or $\geq 1$ SLE diagnosis PLUS $\geq 1$ lupus nephritis proven on renal pathology report review; 2 ) at least 2 clinical visits on record; 3) ECG information available; and 4) those residing locally in the boroughs of Manhattan and Bronx (to increase the likelihood of having patients with continuous and multidisciplinary care at CUIMC). Exclusion criteria were as follows: 1) major ST-T changes/bundle branch block on ECG, 2) prior CVD, and 3) missing documentation of medications. These criteria are summarized in Fig. 1.

\section{RA cohorts}

Two established RA cohorts were studied: 1) ESCAPE$R A$ (Evaluation of Subclinical Cardiovascular Disease and Predictors of Events in Rheumatoid Arthritis) was a prospective study to investigate subclinical atherosclerosis in an RA cohort without clinical CV disease [16]. Participants were recruited from the Johns Hopkins Arthritis Center and referrals from community rheumatologists between 2004 and 2008. Inclusion criteria were age $>45$ for men and $>50$ for women and fulfillment of the 1987 ACR RA classification criteria [17]. 2) RHYTHM-RA (RHeumatoid arthritis: studY of The Myocardium) is a cross-sectional study (subsequently extended to 4-6year follow-up) of myocardial phenotypes in RA patients without clinical CVD recruited from CUIMC and local rheumatology clinics between 2011 and 2020. Inclusion criteria included age $\geq 18$ years old and fulfillment of 2010 ACR RA classification criteria [15]. In both RA cohorts, ECGs were obtained during the first study visit.

\section{Outcome measure QTc length}

The 12-lead ECGs $(25 \mathrm{~mm} / \mathrm{s}$ paper speed and $10 \mathrm{~mm} /$ $\mathrm{mV}$ amplitude) obtained at the first/baseline study visits (RA) and regular clinical care (SLE) were interpreted by a board-certified cardiologist (PP) with specialization in electrophysiology blinded to diagnosis. The QT-interval was calculated and adjusted for the heart rate using Bazett's formula (QTc $=\mathrm{QT} / \sqrt{ } \mathrm{RR}$ ) [18] and evaluated both as a continuous variable and as a binary variable using cutoffs of $\geq 440$ and $\geq 500 \mathrm{~ms}$. These cutoffs have been associated with an increased risk of clinical cardiac events including myocardial infarction, cardiac arrest, and stroke, as well as sudden cardiac death [19-21]. 


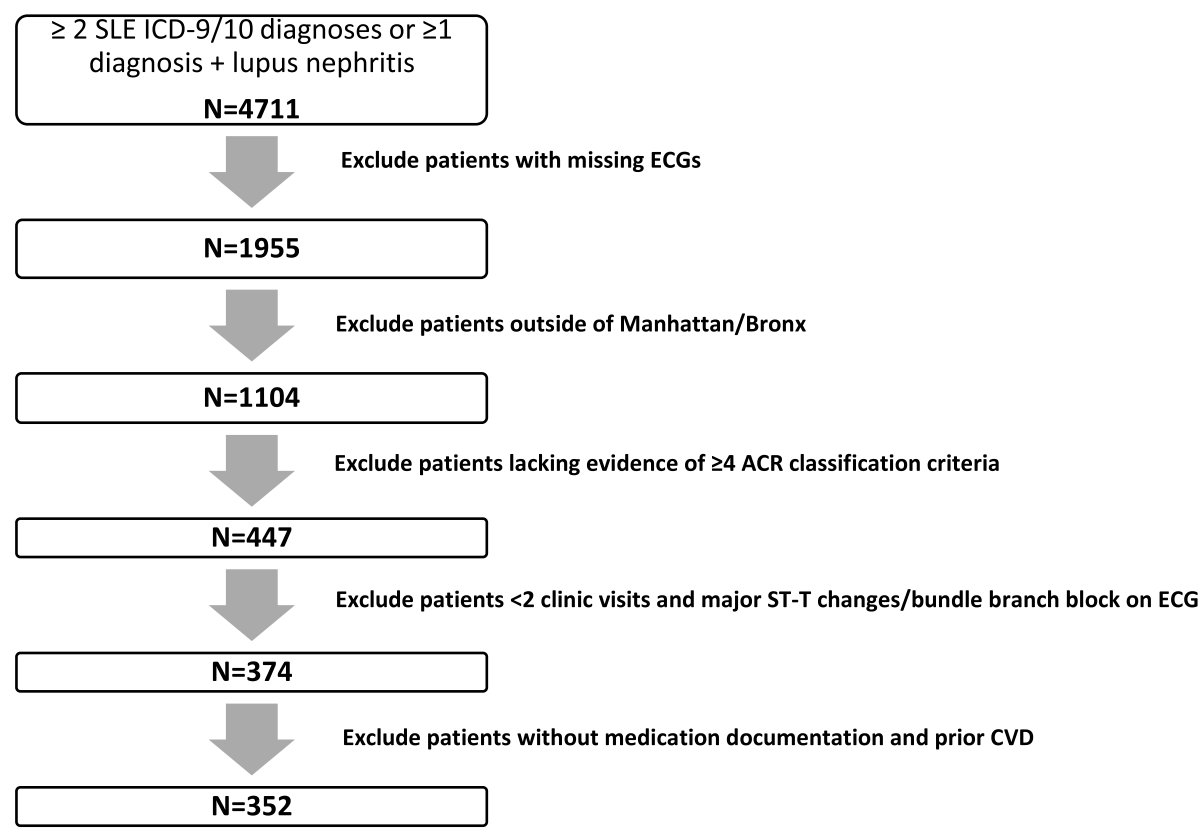

Fig. 1 Columbia University Lupus Cohort

\section{Clinical covariates}

\section{SLE}

Patient characteristics and medications were collected from chart review. SLE disease duration was calculated as the duration in years from the date of physician diagnosis. Medication data were ascertained via clinician notes from the Electronic Medical Record (EMR). All medication data including HCQ use were ascertained at the time of the ECG.

\section{RA cohorts (ESCAPE-RA/RHYTHM)}

Patient characteristics and medications were obtained through study patient questionnaires. RA disease duration was assessed by patient self-report of the date of diagnosis. Medication data was ascertained from medication bottles, and HCQ use was ascertained the time of the ECG. Information regarding cumulative dosage or length of therapy for HCQ were not available for both SLE and RA cohorts. Hypertension was defined as a systolic blood pressure (BP) of $\geq 140 \mathrm{~mm} \mathrm{Hg}$ or diastolic BP of $\geq 90 \mathrm{~mm} \mathrm{Hg}$ or use of antihypertensives at the time of the evaluation. Diabetes was defined as a fasting serum glucose of $\geq 126 \mathrm{mg} / \mathrm{dL}$ or glycosylated hemoglobin (HbA1c) greater than $6.4 \%$ or antidiabetic medication use. QT-modifying medications were defined as any medication included in the following categories: antidepressants, antipsychotics, antiarrhythmics, muscle relaxants, antimicrobials (antivirals/macrolides/fluoroquinolones), tacrolimus, anticonvulsants, and antiemetics. Medication data (clearly noted as taking in EMR or study visits) was recorded in $76 \%$ of biologics, $92 \%$ of steroids, $77 \%$ of statin, $79 \%$ of aspirin, and $38 \%$ of any QTc prolonging medications. If QTc prolonging medication use (categorical variable) was not reported on the medication list, it was assumed that the patient was not on QTc prolonging medications.

\section{Laboratory covariates}

SLE

Laboratory measures, including anti-cardiolipin IgG/ IgM (acL IgG/IgM), anti-nuclear antigen (ANA), antiextra nuclear antigen (anti-ENA), double strand DNA antibody, lupus anticoagulant (LAC), anti-Sjogren's syndrome type a/b antibody (SSA/SSB), anti-Smith, U1 small nuclear ribonucleoprotein antibody (U1-RNP), C-reactive protein (CRP), and complement levels (C3, C4) were collected from the EMR.

\section{$R A$ cohorts (ESCAPE-RA/RHYTHM)}

Rheumatoid factor (seropositivity $\geq 40$ units; IBL America, Minneapolis, MN) and anti-CCP (anticyclic citrullinated peptide antibody) (seropositivity $\geq 60$ units; Inova Diagnostics, Woburn, MA) were measured using enzyme-linked immunosorbent assay (ELISA). The levels of $\mathrm{C}$-reactive protein (CRP) were measured in the Biomarkers Core Laboratory of the CUIMC Clinical and Translational Research Center. 


\section{Statistical analysis}

Variables were summarized and compared using Student's $t$ tests if normally distributed, Wilcoxon rank-sum tests for non-normally distributed variables, or $\chi^{2}$ or Fisher's exact tests for categorical variables. Linear and logistic regression were used to model the associations of clinical and laboratory covariates with QTc length (continuous), and with QTc $\geq 440 \mathrm{~ms}$ and QTc $\geq 500 \mathrm{~ms}$, respectively. Multivariable models were constructed by including any covariate significantly $(p<0.25)$ associated with the primary outcomes (QTc length, QTc $\geq 440 \mathrm{~ms}$, $\mathrm{QTc} \geq 500 \mathrm{~ms}$ ) in univariate regression models. All analyses were performed using Stata version 15 (StataCorp, College Station, TX).

Multiple chained imputations were used to impute medication use for those with missing data for medications associated with QTc length (continuous) and QTc $\geq$ 440 and $\geq 500$.

\section{Results}

\section{Patient population}

Patient disease characteristics, medications, and CV risk factors of combined SLE and RA cohorts are summarized in Table 1. Of the 530 study patients included in the

Table 1 Baseline characteristics SLE + RA ( $N=530)$ stratified by HCQ use

\begin{tabular}{|c|c|c|c|}
\hline Clinical characteristics & $\mathrm{HCQ}(N=371)$ & NO HCQ $(N=159)$ & $p$ value \\
\hline \multicolumn{4}{|l|}{ Demographics } \\
\hline Female $n(\%)$ & 329 (89) & $136(87)$ & 0.51 \\
\hline Age (mean \pm SD) & $46.3(14.1)$ & $55.3(13.1)$ & $<0.005$ \\
\hline \multicolumn{4}{|l|}{ Race } \\
\hline White $n$ (\%) & $83(23)$ & $57(37)$ & 0.001 \\
\hline Black $n(\%)$ & $107(29)$ & $33(21)$ & 0.052 \\
\hline Hispanic $n(\%)$ & $166(46)$ & $60(38)$ & 0.13 \\
\hline Other $n(\%)$ & $8(2)$ & $6(3.8)$ & 0.29 \\
\hline \multicolumn{4}{|l|}{ Disease characteristics } \\
\hline Disease duration years (mean \pm SD) & $12.4(9.03)$ & $11.5(12.3)$ & 0.43 \\
\hline \multicolumn{4}{|l|}{ Immunosuppressant use } \\
\hline Current biologics use $n /$ total (\%) & $67 / 238(28.1)$ & $59 / 159(37.1)$ & 0.060 \\
\hline Current steroid use $n$ /total (\%) & 293/340 (86.2) & $61 / 159(38.4)$ & $<0.005$ \\
\hline \multicolumn{4}{|l|}{ CVD risk factors } \\
\hline Hypertension $n /$ total (\%) & $170 / 369(46.1)$ & 76/155 (49) & 0.54 \\
\hline Diabetes mellitus $n$ /total (\%) & $25 / 368(7)$ & 20/154(13) & 0.02 \\
\hline Current smoking $n /$ total (\%) & $23 / 371(6.2)$ & 15/158 (9.5) & 0.18 \\
\hline Current statin use $n /$ total (\%) & $79 / 244(32.4)$ & $30 / 159(18.9)$ & 0.003 \\
\hline Current aspirin use $n /$ total (\%) & $147 / 257(57.2)$ & 31/159(19.5) & $<0.005$ \\
\hline Ejection fraction $\%$ (mean $\pm S D$ ) & $58.1 \pm 9.4$ & $62.2 \pm 5.1$ & $<0.005$ \\
\hline Ejection fraction $\geq 55 \% n /$ total $(\%)$ & 337/371 (90.8) & $150 / 159(93.3)$ & 0.18 \\
\hline QTc average (mean \pm SD) & $434 \pm 25.7$ & $441 \pm 30.3$ & 0.0079 \\
\hline QTC $\geq 440 n(\%)$ & $134 / 371(36.1)$ & $86 / 159(54.1)$ & $<0.005$ \\
\hline $\mathrm{QTC} \geq 500 n(\%)$ & 13/371 (3.5) & $23 / 159(14.5)$ & $<0.005$ \\
\hline \multicolumn{4}{|l|}{ QTc Meds } \\
\hline Any QTc meds $n$ /total (\%) & $170 / 368(46.2)$ & $52 / 148(35.1)$ & 0.022 \\
\hline Antidepressants $n /$ total (\%) & $61 / 173(35.3)$ & $32 / 44(72.7)$ & $<0.005$ \\
\hline Antipsychotics $n /$ total (\%) & $15 / 150(10)$ & $4 / 18(22.2)$ & 0.13 \\
\hline Antiarrhythmics $n /$ total (\%) & $3 / 145(2.07)$ & $8 / 25(32)$ & $<0.01$ \\
\hline Muscle relaxants $n /$ total (\%) & $11 / 148(7.4)$ & $5 / 22(22.7)$ & 0.038 \\
\hline Antimicrobials $n /$ total (\%) & $83 / 157(52.9)$ & $12 / 20(60)$ & 0.55 \\
\hline Tacrolimus n/total (\%) & 26/155 (16.77) & $1 / 17(5.9)$ & 0.21 \\
\hline Anticonvulsants $n /$ total (\%) & 17/147(11.6) & $1 / 18(5.6)$ & 0.39 \\
\hline Antiemetics n/total (\%) & $54 / 149(36.2)$ & $11 / 20(55 \%)$ & 0.10 \\
\hline
\end{tabular}


study, $371(70 \%)$ reported HCQ use at the time of ECG assessment. In the combined SLE/RA cohort, the mean QTc was $437 \pm 29 \mathrm{~ms}$. The mean QTc measurements for the SLE and RA cohorts were $432 \pm 23 \mathrm{~ms}$ and $444 \pm$ $33 \mathrm{~ms}$, respectively. Forty-four percent of the combined group had a QTc $\geq 440 \mathrm{~ms}$, and $7 \%$ had a QTc $\geq 500 \mathrm{~ms}$. On average, the cohort was middle aged ( $51 \pm 14$ years), predominantly female (83\%), and non-white race (combined Black, Hispanic, and other race $62 \%$ ). The median disease duration was 12 years, and $65 \%$ were on glucocorticoids. Hypertension was reported in $46 \%$, while $39 \%$ were on other QTc prolonging medications. On stratification by HCQ use, HCQ users were significantly younger and used more glucocorticoids and statins $(p<$ $0.005)$ than non-HCQ users. No arrhythmic episodes or associated deaths were reported during the study periods for the RA or the SLE cohorts (2011-2020 and 20152019, respectively).

\section{Association between HCQ use and QTc}

In an adjusted multivariable model, current use of HCQ was not significantly associated with mean QTc length (Table 2), as the mean adjusted QTc was $438 \mathrm{~ms}$ vs $437 \mathrm{~ms}$ for HCQ vs non-HCQ users, respectively) (Fig. 2). In the SLE only cohort, adjusted QTc was comparable in HCQ vs non-HCQ users (433 ms vs $427 \mathrm{~ms}$, respectively) (Fig. 3). Similarly, in the RA only cohort, adjusted QTc was comparable in HCQ vs non-HCQ users $(450 \mathrm{~ms}$ vs $443 \mathrm{~ms}$ ) (Fig. 4). HCQ use was not a significant predictor of a $\mathrm{QTc} \geq 440 \mathrm{~ms}$ for the combined cohort $(\mathrm{OR}=0.77$; 95\% CI 0.48-1.23, $p=0.27$ ) (Table 3) in multivariable logistic models. Current HCQ use was inversely associated with $\mathrm{QTc} \geq 500 \mathrm{~ms}(\mathrm{OR}=0.39 ; 95 \%$ CI $0.16-0.98 ; p$ $=0.044)($ Table 4).

\section{Significant associations with QTc length}

In multivariable models, age, current prednisone use, and current smoking were significantly associated with QTc length (Table 2). Current prednisone use and current aspirin use were significantly associated with QTc $\geq$ $440 \mathrm{~ms}$ (Table 3). The only significant predictor of QTc $\geq$ $500 \mathrm{~ms}$ was current use of tacrolimus (Table 4).

\section{Subgroup analyses SLE only cohort}

In the SLE cohort, HCQ use was not a significant predictor of QTc length (Supplementary Table 3) or a QTc $\geq$ $440 \mathrm{~ms}$ (Supplementary Table 4). However, of the 11 SLE patients with QTc $\geq 500 \mathrm{~ms}$, 9/11 were reported to be on HCQ. Given the small sample size, statistically significant differences could not be ascertained between the HCQ groups with a QTc $\geq 500 \mathrm{~ms}$, yet no arrhythmias or associated deaths were reported, as per retrospective chart
Table 2 Associations of clinical characteristics with QTc length in combined SLE/RA cohort

\begin{tabular}{|c|c|c|c|c|}
\hline \multirow[t]{2}{*}{ Clinical covariates } & \multicolumn{2}{|c|}{$\begin{array}{l}\text { Univariable } \\
\text { model QTc } \\
\text { (continuous) } \\
\end{array}$} & \multicolumn{2}{|c|}{$\begin{array}{l}\text { Multivariable } \\
\text { model QTc } \\
\text { (continuous) }^{\mathrm{a}}\end{array}$} \\
\hline & $B$ & $p$ & $B$ & $p$ \\
\hline Age & 0.38 & $<0.005$ & 0.21 & 0.033 \\
\hline Sex & 0.31 & 0.92 & --------- & $---1-1$ \\
\hline Race (white vs non-white) & 6.2 & $<0.05$ & -0.29 & 0.92 \\
\hline Disease duration (square root) & -0.1 & 0.86 & --------- & ------ \\
\hline Current $\mathrm{HCQ}$ use & -7.8 & $<0.005$ & 0.22 & 0.95 \\
\hline Current prednisone use & -9.8 & $<0.005$ & -8.27 & 0.018 \\
\hline Current biologic use & 0.45 & 0.87 & --------- & 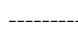 \\
\hline Hypertension & 3.6 & 0.11 & 3.01 & 0.29 \\
\hline Current smoking & 10.6 & $<0.05$ & 10.2 & 0.033 \\
\hline Diabetes & 8.9 & $<0.05$ & 0.69 & 0.88 \\
\hline Current statin use & 2.7 & 0.38 & & ----- \\
\hline Current aspirin use & -7.1 & $<0.05$ & -3.9 & 0.22 \\
\hline Any QTc meds & -1.4 & 0.56 & --------- & 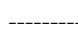 \\
\hline Antidepressants & 7.1 & $<0.05$ & & \\
\hline Antipsychotics & -1.6 & 0.80 & & \\
\hline Antiarrhythmics & 5.4 & 0.49 & & \\
\hline Muscle relaxants & 9.6 & 0.12 & ---------- & ------ \\
\hline Antimicrobials & -0.2 & 0.96 & -2.4 & 0.46 \\
\hline Antiemetics & 1.8 & 0.63 & & \\
\hline Anticonvulsants & 7.9 & 0.21 & & \\
\hline Tacrolimus & -0.5 & 0.92 & ------- & \\
\hline Ejection fraction \% & 0.05 & 0.77 & -------- & ------ \\
\hline Ejection fraction $\geq 55 \%$ & -3.2 & 0.47 & -------- & 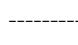 \\
\hline Prob $>F$ & ------ & & 0.0001 & \\
\hline
\end{tabular}

Abbreviations: HCQ hydroxychloroquine, QtC QT corrected interval

${ }^{\text {a }}$ Final imputed data

review over 4 years. In multivariable analyses, elevated CRP level $(\geq 10.0 \mathrm{mg} / \mathrm{L})$ was significantly associated with QTc length, and diabetes and use of any QTc prolonging medications were significantly associated with QTc $\geq$ $440 \mathrm{~ms}$ (Supplementary Table 4). Adjusted QTc was comparable in the HCQ vs non-HCQ users groups (433 ms vs $429 \mathrm{~ms}$, respectively) (Fig. 3).

\section{RA only cohorts}

In the RA cohorts analyzed separately, HCQ use was a significant predictor of QTc length (Supplementary Table 6), and adjusted QTc was longer in HCQ vs nonHCQ users (462 ms vs $443 \mathrm{~ms}$, respectively) (Fig. 4). However, HCQ use was not a predictor of QTc $\geq 440$ ( $p=$ $0.79)$ or $\geq 500 \mathrm{~ms}(p=0.41)$ (Supplementary Tables 7 and 8). Notably, significant predictors of prolonged QTc $\geq$ $500 \mathrm{~ms}$ included age, current smoking, and diabetes (Supplementary Table 8). 


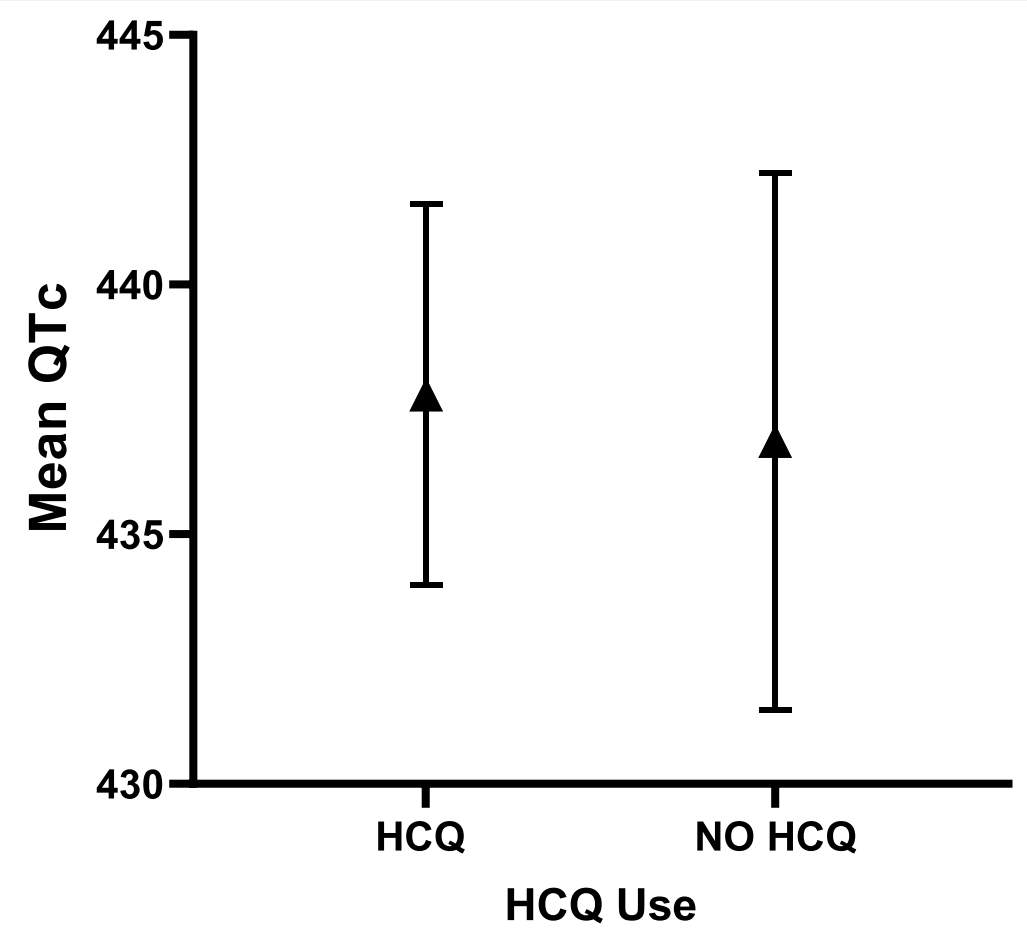

Fig. 2 Adjusted QTC length and $95 \% \mathrm{Cl}$ in HCQ vs. NO HCQ in combined SLE/RA cohorts

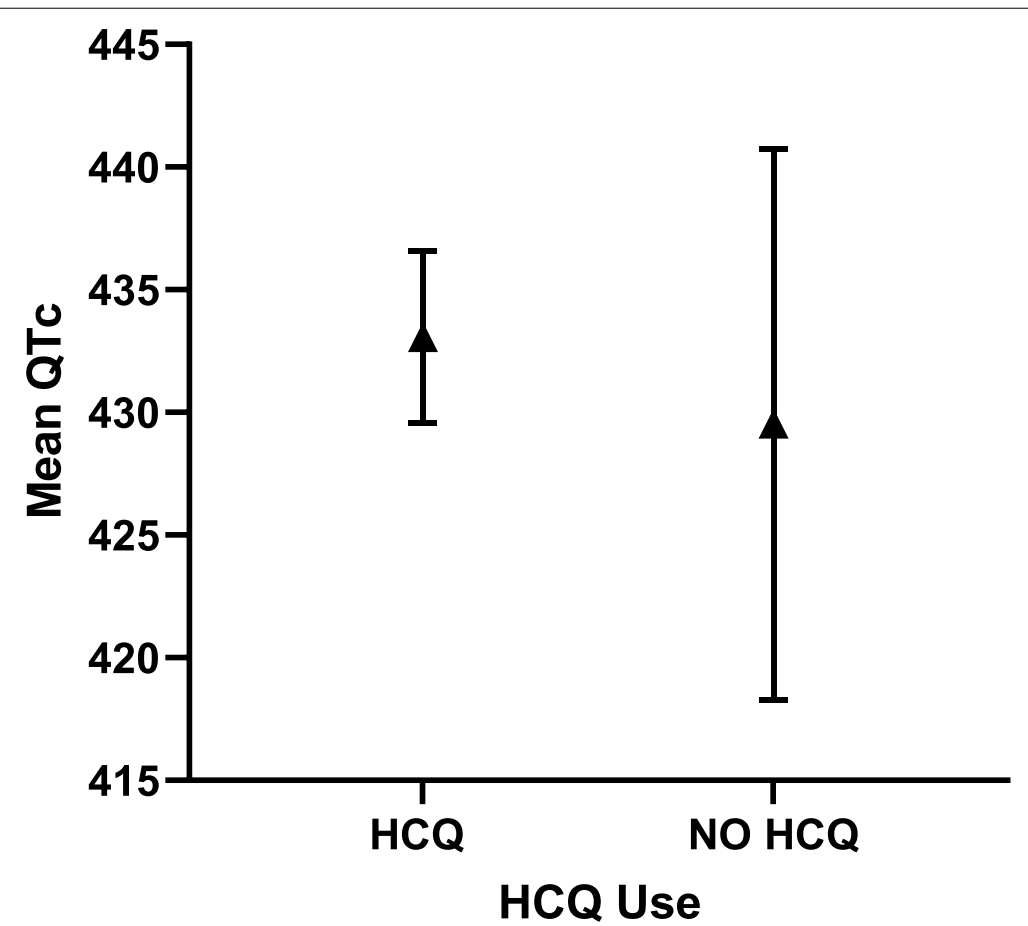

Fig. 3 Adjusted QTC length and 95\% Cl in HCQ vs. NO HCQ in SLE cohort 


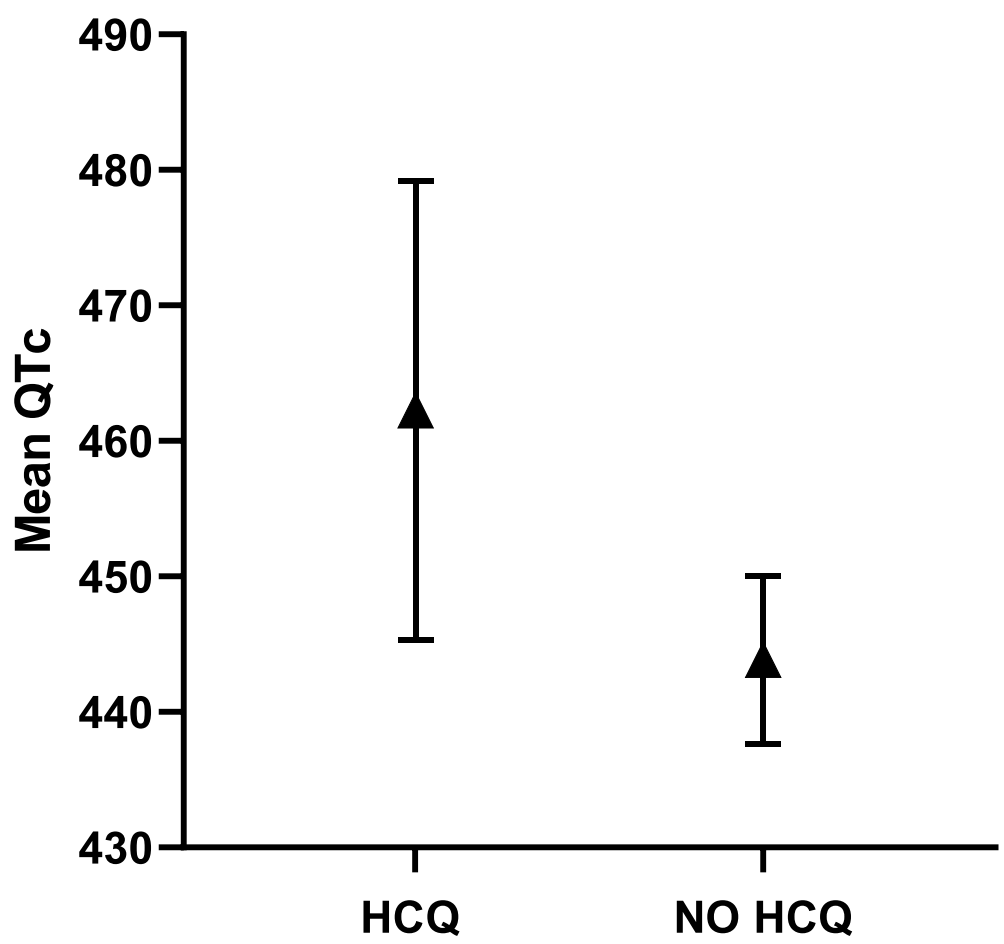

Fig. 4 Adjusted QTc length and 95\% Cl in HCQ vs. NO HCQ in RA cohort

\section{HCQ Use}

\section{Interaction with other QTC prolonging medications}

In the combined RA + SLE cohort, a significant interaction was found between HCQ use and use of anti-psychotics (Table 5), with QTc length being longer in those on both vs only HCQ (439 ms vs $432 \mathrm{~ms}$; Fig. 5). Overall, QTc length was comparable in those on HCQ + any QTc prolonging medications vs only HCQ (434 ms vs $433 \mathrm{~ms}$; Fig. 6). When stratified by RA vs SLE cohort, no significant interactions were found between HCQ use and use of any QTc medications (Supplementary Table 9-10).

\section{Discussion}

In this large cohort of RA and SLE patients, HCQ use was not associated with QTc length when adjusted for potential confounders such as age and other medications affecting QTc length. The adjusted QTc length was comparable between HCQ users and non-users (438 ms vs $437 \mathrm{~ms}$ ). Although up to $44 \%$ of the combined cohort had a QTc $\geq 440 \mathrm{~ms}, \mathrm{HCQ}$ use was not a predictor of prolonged QTc.

QTc length as an outcome remains of paramount interest, since in the general population and in selected subpopulations (i.e., the elderly, patients with coronary artery disease, and the critically ill), prolonged QTc length (defined in those studies as $>450 \mathrm{~ms}$ in men and $>470 \mathrm{~ms}$ in women) independently predicts sudden cardiac death $[19,20]$. In fact, even moderate QTc prolongation between 420 and $440 \mathrm{~ms}$ has been associated with all-cause mortality [21]. In a retrospective cohort study of RA patients, idiopathic QTc prolongation [22] was associated with an almost $30 \%$ increase in all-cause mortality (HR 1.28; 95\% CI 0.91-1.81, $p=0.16$ ). Furthermore, in a prospective cohort of RA patients, a 50-ms increase in QTc interval was independently associated with a twofold risk of mortality $(\mathrm{HR}=2.18,95 \%$ CI 1.09 , 4.35), and CRP levels were also independently associated with QTc length [10]. In our study, prednisone use was associated with a lower QTc length in the combined $\mathrm{RA}+$ SLE cohort, in addition to being a negative predictor of QTc $\geq 440 \mathrm{~ms}$. From this observation, we hypothesize that reduction of systemic inflammation mitigated any deleterious effects on the conduction system and thus decreased the risk of QTc prolongation. However, when we examined these associations separately by individual cohorts, in the SLE cohort, CRP > 10 mg/L and not prednisone use was associated with (higher) QTc length. Given that $79 \%$ of our SLE cohort demonstrated CRP > $10 \mathrm{mg} / \mathrm{L}$, despite $93 \%$ using prednisone, we postulate that in this group, high disease activity (and thus 
Table 3 Associations of clinical characteristics with QTC $\geq 440 \mathrm{~ms}$ in combined SLE/RA cohort

\begin{tabular}{|c|c|c|c|c|c|c|}
\hline \multirow[t]{2}{*}{ Clinical covariates } & \multicolumn{3}{|c|}{ Univariable model QTc $\geq 440 \mathrm{~ms}$} & \multicolumn{3}{|c|}{ Multivariable model QTc $\geq 440 \mathrm{~ms}^{\mathrm{b}}$} \\
\hline & $O R$ & $95 \% \mathrm{Cl}$ & $p$ & $O R$ & $95 \% \mathrm{Cl}$ & $p$ \\
\hline Age & 1.02 & $1.00-1.03$ & 0.004 & 1.00 & $0.99-1.02$ & 0.53 \\
\hline Sex & 1.29 & $0.86-1.96$ & 0.22 & -------- & --------- & $----1-$ \\
\hline Race (white vs non-white) & 1.48 & $1.07-2.03$ & 0.016 & 1.06 & $0.68-1.63$ & 0.80 \\
\hline Disease duration (square root) & 0.96 & $0.86-1.07$ & 0.48 & --------- & ---------- & -------1. \\
\hline Current $\mathrm{HCQ}$ use & 0.48 & $0.33-0.70$ & $<0.01$ & 0.77 & $0.48-1.23$ & 0.27 \\
\hline Current prednisone use & 0.46 & $0.33-0.64$ & $<0.01$ & 0.56 & $0.34-0.92$ & 0.023 \\
\hline Current biologic use & 0.83 & $0.58-1.19$ & 0.30 & --------- & ---------- & ------1 \\
\hline Hypertension & 1.18 & $0.87-1.61$ & 0.29 & --------- & ---------- & ------ \\
\hline Current smoking & 1.46 & $0.82-2.60$ & 0.20 & -------- & ---------- & --1- \\
\hline Diabetes & 1.64 & $0.95-2.83$ & 0.076 & 1.38 & $0.70-2.72$ & 0.35 \\
\hline Current statin use & 1.08 & $0.73-1.60$ & 0.69 & -------- & ---------- & ------- \\
\hline Current ASA use & 0.51 & $0.36-0.73$ & $<0.01$ & 0.68 & $0.43-1.07$ & 0.095 \\
\hline Any QTc meds & 1.07 & $0.78-1.47$ & 0.67 & ------- & --------- & --1- \\
\hline Antidepressants & 1.79 & $1.07-2.99$ & 0.027 & 1.45 & $0.90-2.33$ & 0.12 \\
\hline Antipsychotics & 1.62 & $0.62-4.22$ & 0.33 & --------- & ---------- & ------- \\
\hline Antiarrhythmics & 1.48 & $0.43-5.06$ & 0.53 & ---------- & & \\
\hline Muscle relaxants & 1.41 & $0.57-3.46$ & 0.46 & ------- & -------- & --1- \\
\hline Antimicrobials & 0.99 & $0.62-1.58$ & 0.97 & ------ & 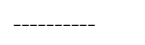 & ----- \\
\hline Antiemetics & 1.15 & $0.63-2.08$ & 0.65 & ------- & ------- & -------. \\
\hline Anticonvulsants & 2.33 & $0.54-1.93$ & 0.94 & --------- & --------- & -------- \\
\hline Tacrolimus & 1.63 & $0.72-3.69$ & 0.24 & --- & -ב--- & - \\
\hline Ejection fraction \% & 1.00 & $0.98-1.03$ & 0.82 & ------ & ------ & ------ \\
\hline Ejection fraction $\geq 55 \%$ & 0.81 & $0.44-1.49$ & 0.50 & -------- & -------- & -------- \\
\hline Prob $>F$ & ------ & & & 0.0001 & & \\
\hline
\end{tabular}

Abbreviations: HCQ hydroxychloroquine, QTCMeds QTc prolonging medications

${ }^{\mathrm{b}}$ Final imputed data

inflammatory) burden, unmitigated by prednisone use, increased the risk of QTc prolongation. The specific interplay between inflammation and arrhythmogenic potential, as well as mechanisms leading to arrhythmia, merits further exploration.

HCQ-associated QTc prolongation and subsequent arrhythmia development received considerable attention during its widespread use in COVID-19 patients. In an uncontrolled study of COVID-19 patients receiving HCQ alone or HCQ and azithromycin for associated pneumonia [8], baseline to treatment change in QTc was higher in the HCQ + azithromycin group vs HCQ alone. It is also worthwhile noting that in the prior study, up to $19 \%$ of those receiving HCQ alone had a QTc > $500 \mathrm{~ms}$ (and 21\% in combination group) and $8 \%$ had a clinically significant increase $>60 \mathrm{~ms}$, with one episode of torsades de pointes reported. However, independent effects of COVID-19 infection on the cardiac conduction system [9] and indication bias (severe COVID-19 patients more likely to receive $\mathrm{HCQ}$ ) must be considered in interpretation of these data. Similarly, Ramireddy et al. [23] reported a significantly higher change in QTc from baseline to treatment in the HCQ and azithromycin group vs HCQ alone (17 $\pm 39 \mathrm{~ms}$ vs $0.5 \pm 40 \mathrm{~ms} ; p=0.07$ ). More concerning, up to $12 \%$ of total patients in this study (receiving HCQ alone, azithromycin alone, or both) had critical QTc prolongation (defined as maximum QTc $\geq 500 \mathrm{~ms}$ (if QRS $<120 \mathrm{~ms}$ ) or QTc $\geq 550 \mathrm{~ms}$ (if QRS $\geq 120 \mathrm{~ms}$ ) and QTc increase of $\geq 60 \mathrm{~ms}$ ); however, no torsades de pointes was documented. The results of a more recent randomized controlled trial [24] were more reassuring in that, in 1561 COVID patients randomized to the HCQ arm and loaded with high doses of HCQ $(800 \mathrm{mg} \times 2$ doses followed by $400 \mathrm{mg}$ every $12 \mathrm{~h}$ for 9 days or until discharge), there were no significant differences in terms of frequency of arrhythmias compared to the usual care group.

As for rheumatologic patients, SLE patients treated with high cumulative doses (700-1300 g) of antimalarials from several months to decades demonstrated bundle branch block and third-degree AV block (with some leading to Torsades de Pointes) [25-28]. However, interpretation from these case reports is limited due to absence of 
Table 4 Associations of clinical characteristics with QTC $\geq 500 \mathrm{~ms}$ in combined SLE/RA cohort

\begin{tabular}{|c|c|c|c|c|c|c|}
\hline \multirow[t]{2}{*}{ Clinical covariates } & \multicolumn{3}{|c|}{ Univariable model QTc $\geq 500 \mathrm{~ms}$} & \multicolumn{3}{|c|}{ Multivariable model QTc $\geq 500 \mathrm{~ms}^{\mathrm{c}}$} \\
\hline & $O R$ & $95 \% \mathrm{Cl}$ & $p$ & OR & $95 \% \mathrm{Cl}$ & $p$ \\
\hline Age & 0.99 & $0.96-1.01$ & 0.25 & --------- & --------- & --1-1- \\
\hline Sex & 1.12 & $0.49-2.57$ & 0.79 & - & 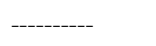 & ----- \\
\hline Race (white vs non-white) & 0.92 & $0.48-1.76$ & 0.79 & ------ & 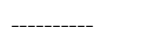 & - \\
\hline Disease duration (square root) & 0.86 & $0.69-1.07$ & 0.17 & --------- & ---------- & -------- \\
\hline Current HCQ use & 0.21 & $0.11-0.44$ & $<0.01$ & 0.39 & $0.16-0.98$ & 0.044 \\
\hline Current prednisone use & 0.43 & $0.23-0.81$ & 0.010 & 0.55 & $0.23-1.34$ & 0.19 \\
\hline Current biologic use & 0.94 & $0.48-1.85$ & 0.86 & --------- & --------- & - \\
\hline Hypertension & 1.37 & $0.74-2.55$ & 0.31 & --------- & -------- & ------ \\
\hline Current smoking & 2.71 & $1.13-6.45$ & 0.025 & 2.23 & $0.80-6.15$ & 0.12 \\
\hline Diabetes & 2.73 & $1.20-6.23$ & 0.017 & 1.47 & $0.47-4.63$ & 0.51 \\
\hline Current statin use & 0.56 & $0.24-1.29$ & 0.17 & --------- & --------- & ------ \\
\hline Current aspirin use & 0.39 & $0.18-0.83$ & 0.015 & 0.60 & $0.23-1.56$ & 0.29 \\
\hline Any QTc meds & 1.14 & $0.63-2.07$ & 0.66 & ------- & -------- & - \\
\hline Antidepressants & 2.41 & $0.88-6.56$ & 0.085 & 1.30 & $0.52-3.23$ & 0.58 \\
\hline Antipsychotics & 1.14 & $0.13-9.83$ & 0.90 & --------- & ---------- & --1- \\
\hline Antiarrhythmics & 2.20 & $0.25-19.67$ & 0.48 & --------- & -------- & --- \\
\hline Muscle relaxants & 3.36 & $0.80-14.10$ & 0.098 & 3.04 & $0.68-13.63$ & 0.15 \\
\hline Antimicrobials & 0.55 & $0.15-2.01$ & 0.36 & ------- & --------- & ----1- \\
\hline Antiemetics & 1.0 & ---------- & --_- & ------- & -------- & ------ \\
\hline Anticonvulsants & 1.19 & $0.14-10.29$ & 0.87 & --------- & --------- & ------- \\
\hline Tacrolimus & 4.29 & $0.90-20.33$ & 0.067 & 4.31 & $1.06-17.53$ & 0.042 \\
\hline Ejection fraction \% & 1.07 & $0.99-1.15$ & 0.060 & 1.05 & $0.96-1.14$ & 0.31 \\
\hline Ejection fraction $\geq 55 \%$ & 1.79 & $0.42-7.63$ & 0.43 & --------- & ---------- & --1--1- \\
\hline Prob $>F$ & - & & & 0.0066 & & \\
\hline
\end{tabular}

Abbreviations: HCQ hydroxychloroquine, QTCMeds QTc prolonging medications

'Final imputed data

Table 5 Interactions in combined SLE/RA cohort

\begin{tabular}{lll}
\hline QTc & $B$ & $\boldsymbol{p}$ \\
\hline Current HCQ Use\#AnyQTcMeds & 3.70 & 0.52 \\
Current HCQ Use\#Antidepressants & 4.35 & 0.65 \\
Current HCQ Use\#Antipsychotics & $\mathbf{4 0 . 1}$ & $\mathbf{0 . 0 1}$ \\
Current HCQ Use\#Antiarrhythmics & 7.46 & 0.68 \\
Current HCQ Use\#Musclerelaxants & -2.95 & 0.89 \\
Current HCQ Use\#Antimicrobials & -1.47 & 0.90 \\
Current HCQ Use\#Antiemetics & 2.97 & 0.80 \\
Current HCQ Use\#Tacrolimus & 22.23 & 0.39 \\
\hline
\end{tabular}

controls. It is also important to note that current trends in HCQ dosing have become more conservative due to heightened awareness of retinal toxicity. More recently, Lane et al. [29] reported no increased risk of cardiac arrhythmias (calibrated HR 0.90; 95\% CI 0.78-1.03; $p<$ 0.01 ) in HCQ users ( $400 \mathrm{mg} /$ day for 30 days) vs sulfasalazine users in a retrospective review of 14 multinational databases of RA patients. Liu et al. [30] reported a lower risk of $\mathrm{CV}$ disease including sudden cardiac arrest/death in $\mathrm{HCQ} /$ chloroquine (CQ) users vs non-users (RR 0.72; $95 \%$ CI $0.56-0.94 ; p=0.013)$ in a meta-analysis of various rheumatologic patients. Various cardioprotective (thromboprotective and cholesterol reducing) effects of $\mathrm{HCQ} / \mathrm{CQ}[31,32]$ may partially explain this finding but the absence of clinical trial data and $\mathrm{CV} /$ metabolic parameters limit interpretation. In another prospective study [33] of RA patients, incidence of long QT syndrome or arrhythmia-related hospitalizations were comparable between HCQ use vs non-HCQ disease-modifying antirheumatic drug (DMARD) use.

Specifically, the lack of association of HCQ use with overall QTc length in our results is consistent with prior publications in RA and SLE patients [10-13, 22]. The main strength of our study is its sample size as it represents one of the largest multiethnic studies inclusive of both SLE and RA patients. Importantly, we accounted for the concurrent use of a wide variety of QTc prolonging or arrhythmogenic medications, which was not 


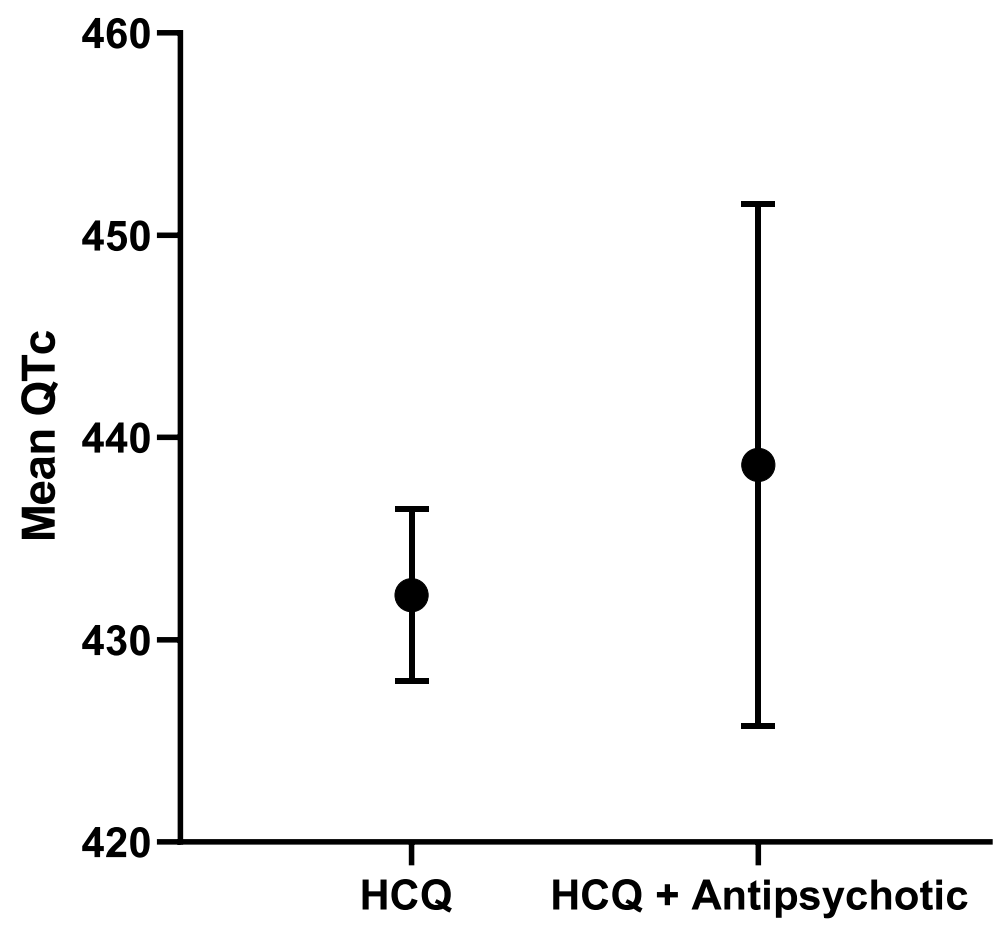

Fig. 5 Mean QTc length and 95\% Cl in HCQ vs. HCQ + antipsychotic in SLE/RA cohort

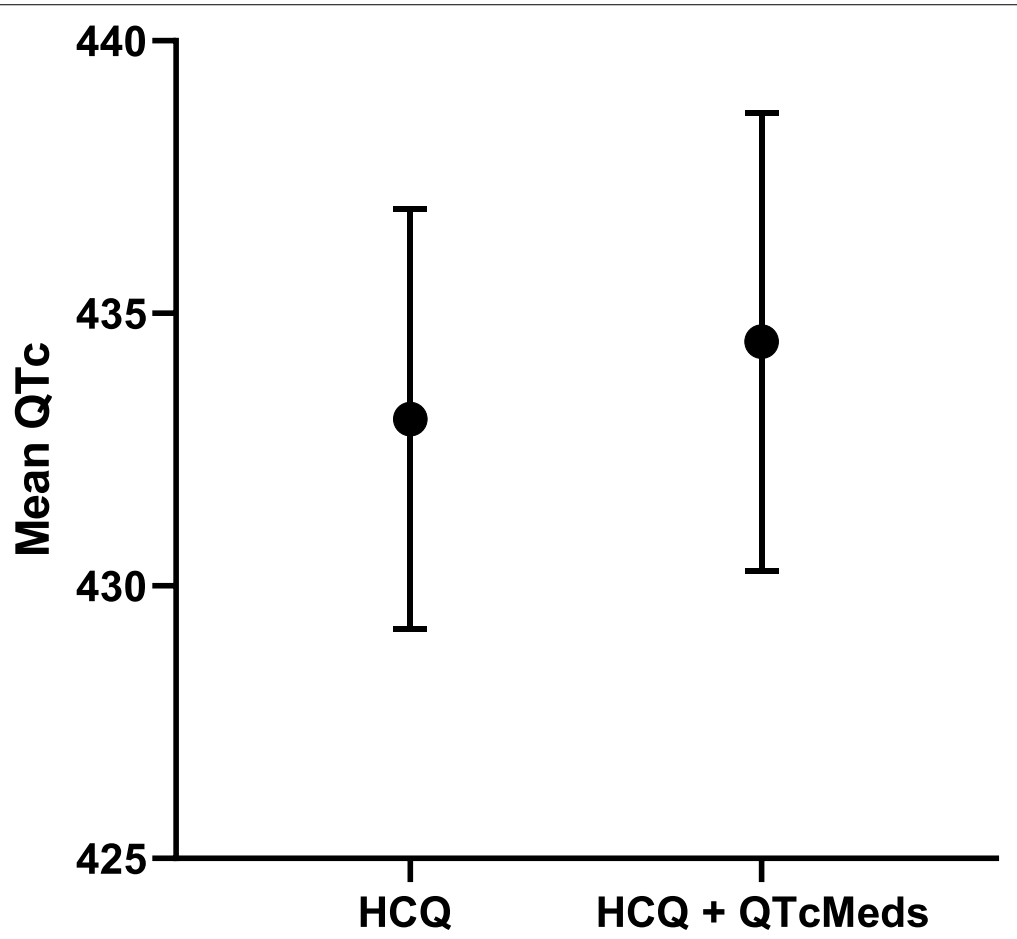

Fig. 6 Mean QTc length and 95\% Cl in HCQ vs. HCQ+QTcMeds in combined SLE/RA cohort 
consistently done in previous literature. Although SLE data were obtained retrospectively via ICD 9/10 codes on EMR review, we restricted analyses to SLE patients who demonstrated consistent care at our institution $(\geq$ 2 visits). For both the SLE and RA cohorts, QTc length was calculated by standardized Bazett's formula and confirmed by a blinded, trained cardiac electrophysiologist (PP). The main limitations of our study include the lack of data on HCQ adherence (i.e., via patient report, and/ or metabolite levels), as well as cumulative dosage or length of therapy, as it is known that HCQ adherence in the SLE population is variably poor and the risk of HCQ toxicity increases with cumulative dosage. Moreover, although we detected a statistically significant interaction between antipsychotics and HCQ use, we acknowledge the small number of observations $(<20$ who reported on both antipsychotic and HCQ use) that may preclude interaction testing as well as produce an overestimation of interaction effect. In addition, we did not obtain or analyze pre-HCQ ECGs (determined only at the time of HCQ use for both SLE and RA cohorts) and therefore cannot make conclusions about preand post-exposure change in QTc length. Finally, because we excluded patients with clinical CVD who received ECG screening, our findings may not directly apply to those patients, who may have other risk factors associated with prolonged QTc. Given the prevalence of associated CV risk factors (hypertension, diabetes), we surmise that our patients likely had some underlying, subclinical CVD.

\section{Conclusions}

In a combined large multiethnic cohort of RA and SLE patients, QTc length did not significantly differ in HCQ users compared with non-HCQ users, nor was it associated with a QTc $\geq 440 \mathrm{~ms}$, even while adjusting for potential confounders. There was a notable statistical interaction between the use of HCQ and use of antipsychotics in the combined RA and SLE cohort. Our data suggests that HCQ does not increase the arrhythmogenic risk for patients with rheumatologic conditions.

\footnotetext{
Abbreviations

AcL IgG/IgM: Anti-cardiolipin IgG/lgM; ACR: American College of Rheumatology; ANA: Anti-nuclear antigen; Anti-CCP: Anticyclic citrullinated peptide antibody; Anti-ENA: Anti-extra nuclear antigen; BP: Blood pressure; COVID-19: Coronavirus disease 19; CQ: Chloroquine; CRP: C-reactive protein; CUIMC: Columbia University Irving Medical Center; CV/D: Cardiovascular disease; DMARD: Disease-modifying anti-rheumatic drug; ECG: Electrocardiograms; ELISA: Enzyme-linked immunosorbent assay; EMR: Electronic Medical Record; ESCAPE-RA: Evaluation of Subclinical Cardiovascular Disease and Predictors of Events in Rheumatoid Arthritis; HbA1c: Glycosylated hemoglobin; HCQ: Hydroxychloroquine; ICD-9/ICD-10: International Classification of Diseases, Ninth and Tenth Revision, Clinical Modification; LAC: Lupus anticoagulant; NYPH: New York Presbyterian Hospitals; QTc: Corrected QT length; RA: Rheumatoid arthritis; RHYTHM-RA: RHeumatoid arthritis: studY of The Myocardium; SLE: Systemic lupus erythematosus; SSA/SSB: Anti-Sjogren's syndrome type a/b antibody; U1-RNP: U1 small nuclear ribonucleoprotein.
}

\section{Supplementary Information}

The online version contains supplementary material available at https://doi. org/10.1186/s13075-021-02646-0.

Additional file 1: Table 1. Baseline Characteristics SLE ( $N=352)$ Stratified by HCQ Use. Table 2. Baseline Characteristics RA ( $N=178)$ Stratified by HCQ Use. Table 3. Associations of Clinical Characteristics with QTC Length in SLE Cohort. Table 4. Associations of Clinical Characteristics with $\mathrm{QTC} \geq 440 \mathrm{~ms}$ in SLE Cohort. Table 5. Associations of Clinical Characteristics with QTc $\geq 500$ ms in SLE Cohort. Table 6. Associations of Clinical Characteristics with QTC Length in RA Cohort. Table 7. Associations of Clinical Characteristics with QTc $\geq 440 \mathrm{~ms}$ in RA Cohort. Table 8. Associations of Clinical Characteristics with QTc $\geq 500$ ms in RA Cohort. Table 9. Interactions in RA Cohort. Table 10. Interactions in SLE Cohort.

\section{Acknowledgements}

Not applicable

\section{Authors' contributions}

JTG, TPR, PP, CD, YG, ADA, JB, and LGP: recruitment and data collection. EP and LGP: constructed analysis plan and first draft of manuscript. EP, JTG, ADA, JB, and LGP: substantial modification of manuscript and final approval. All authors read and approved final manuscript.

\section{Funding}

Joan Bathon is supported by NIH/NIAMS R01 AR050026 and U01 AR068043

\section{Availability of data and materials}

The datasets used and analyzed during the current study are included in this published article (and its supplementary information files) or otherwise available from the corresponding author on request.

\section{Declarations}

Ethics approval and consent to participate

ESCAPE-RA, RHYTHM, and use of data from the Columbia University Lupus Cohort Registry were all approved by the CUIMC/New York Presbyterian Hospital Institutional Review Board.

\section{Consent for publication}

Not applicable

\section{Competing interests}

The authors declare that they have no competing interests.

\section{Author details}

${ }^{1}$ Division of Rheumatology, Columbia University Vagelos College of Physicians and Surgeons and New York Presbyterian Hospital, 630 W 168th St, P\&S 3-450, New York, NY 10032, USA. ${ }^{2}$ Cardiac Electrophysiology, Northwestern Medicine, Chicago, IL, USA.

Received: 22 June 2021 Accepted: 11 October 2021

Published online: 29 October 2021

\section{References}

1. Yogasundaram H, Putko BN, Tien J, Paterson DI, Cujec B, Ringrose J, et al. Hydroxychloroquine-induced cardiomyopathy: case report, pathophysiology, diagnosis, and treatment. Can J Cardiol. 2014;30(12):1706-15.

2. Mackenzie AH. Pharmacologic actions of 4-aminoquinoline compounds. Am J Med. 1983;75(1):5-10.

3. Lazzerini PE, Capecchi PL, Acampa M, Morozzi G, Bellisai F, Bacarelli $M R$, et al. Anti-Ro/SSA-associated corrected QT interval prolongation in adults: the role of antibody level and specificity. Arthritis Care Res. 2011;63(10):1463-70. 
4. Giudicessi JR, Ackerman MJ, Fatkin D, Kovacic JC. Precision medicine approaches to cardiac arrhythmias. J Am Coll Cardiol. 2021;77(20):2573-91.

5. Sumpter M, Tatro L, Stoecker W, Rader R. Evidence for risk of cardiomyopathy with hydroxychloroquine. Lupus. 2012;21(14):1594-6.

6. Traebert M, Dumotier B, Meister L, Hoffmann P, Dominguez-Estevez M, Suter W. Inhibition of hERG K+ currents by antimalarial drugs in stably transfected HEK293 cells. Eur J Pharmacol. 2004;484(1):41-8.

7. Cipriani A, Zorzi A, Ceccato D, Capone F, Parolin M, Donato F, et al. Arrhythmic profile and 24-hour QT interval variability in COVID-19 patients treated with hydroxychloroquine and azithromycin. Int J Cardiol. 2020;316:280-4.

8. Mercuro NJ, Yen CF, Shim DJ, Maher TR, McCoy CM, Zimetbaum PJ, et al. Risk of QT interval prolongation associated with use of hydroxychloroquine with or without concomitant azithromycin among hospitalized patients testing positive for coronavirus disease 2019 (COVID-19). JAMA Cardiol. 2020; [cited 2020 May 27]; Available from: https://jamanetwork. com/journals/jamacardiology/fullarticle/2765631.

9. Hendren NS, Drazner MH, Bozkurt B, Cooper LT. Description and proposed management of the acute COVID-19 cardiovascular syndrome. Circulation. 2020;141(23):1903-14.

10. Panoulas VF, Toms TE, Douglas KMJ, Sandoo A, Metsios GS, StavropoulosKalinoglou A, et al. Prolonged QTc interval predicts all-cause mortality in patients with rheumatoid arthritis: an association driven by high inflammatory burden. Rheumatology. 2014;53(1):131-7.

11. Geraldino-Pardilla L, Gartshteyn Y, Piña P, Cerrone M, Giles JT, Zartoshti A, et al. ECG non-specific ST-T and QTC abnormalities in patients with systemic lupus erythematosus compared with rheumatoid arthritis. Lupus Sci Med. 2016;3(1):e000168.

12. Costedoat-Chalumeau N, Hulot J-S, Amoura Z, Leroux G, Lechat P, FunckBrentano C, et al. Heart conduction disorders related to antimalarials toxicity: an analysis of electrocardiograms in 85 patients treated with hydroxychloroquine for connective tissue diseases. Rheumatology. 2007:46(5):808-10.

13. Nomura A, Kishimoto M, Takahashi O, Deshpande GA, Yamaguchi K, Okada M. Prolongation of heart rate-corrected QT interval is a predictor of cardiac autonomic dysfunction in patients with systemic lupus erythematosus. Rheumatol Int. 2014;34(5):643-7.

14. McGhie TK, Harvey P, Su J, Anderson N, Tomlinson G, Touma Z. Electrocardiogram abnormalities related to anti-malarials in systemic lupus erythematosus. Clin Exp Rheumatol. 2018;36(4):545-51.

15. Aringer M, Costenbader K, Daikh D, Brinks R, Mosca M, Ramsey-Goldman R, et al. 2019 European League Against Rheumatism/American College of Rheumatology Classification Criteria for Systemic Lupus Erythematosus. Arthritis Rheum. 2019;71(9):1400-12.

16. Giles JT, Szklo M, Post W, Petri M, Blumenthal RS, Lam G, et al. Coronary arterial calcification in rheumatoid arthritis: comparison with the MultiEthnic Study of Atherosclerosis. Arthritis Res Ther. 2009;11(2):R36.

17. Arnett FC, Edworthy SM, Bloch DA, Mcshane DJ, Fries JF, Cooper NS, et al. The American rheumatism association 1987 revised criteria for the classification of rheumatoid arthritis. Arthritis Rheum. 1988;31(3):315-24.

18. Goldenberg I, Moss AJ, Zareba W. QT Interval: how to measure it and what is "normal". J Cardiovasc Electrophysiol. 2006;17(3):333-6.

19. Chugh SS, Reinier K, Singh T, Uy-Evanado A, Socoteanu C, Peters D, et al. Determinants of prolonged QT interval and their contribution to sudden death risk in coronary artery disease: the Oregon Sudden Unexpected Death Study. Circulation. 2009;119(5):663-70.

20. Straus SMJM, Kors JA, De Bruin ML, van der Hooft CS, Hofman A, Heeringa J, et al. Prolonged QTC interval and risk of sudden cardiac death in a population of older adults. J Am Coll Cardiol. 2006;47(2):362-7.

21. Schouten EG, Dekker JM, Meppelink P, Kok FJ, Vandenbroucke JP, Pool J. QT interval prolongation predicts cardiovascular mortality in an apparently healthy population. Circulation. 1991;84(4):1516-23.

22. Chauhan K, Ackerman MJ, Crowson CS, Matteson L, Gabriel SE. Population-based study of QT interval prolongation in patients with rheumatoid arthritis. 2016;33(1): 84-89.

23. Ramireddy A, Chugh H, Reinier K, Ebinger J, Park E, Thompson M, et al. Experience with hydroxychloroquine and azithromycin in the coronavirus disease 2019 pandemic: implications for QT interval monitoring. J Am Heart Assoc. 2020;9(12) [cited 2020 Jul 27]. Available from: https://www. ahajournals.org/doi/10.1161/JAHA.120.017144.

24. The RECOVERY Collaborative Group. Effect of hydroxychloroquine in hospitalized patients with COVID-19. N Engl J Med. 2020;383(21):2030-40.

25. Olken D, Volastro P, Finck D, Tulgan H, Mazur P. Heart block in systemic lupus erythematosus complicated by Pacemaker "exit block". Arthritis Rheum. 1991;34(1):121-3.

26. Comí-Colet J, Sánchez-Corral MA, Alegre-Sancho JJ, Valverde J, LópezGómez D, Sabaté X, et al. Complete heart block in an adult with systemic lupus erythematosus and recent onset of hydroxychloroquine therapy. Lupus. 2001;10(1):59-62.

27. Stas P, Faes D, Noyens P. Conduction disorder and QT prolongation secondary to long-term treatment with chloroquine. Int J Cardiol. 2008; 127(2):e80-2.

28. Edwards AC, Meredith TJ, Sowton E. Complete heart block due to chronic chloroquine toxicity managed with permanent pacemaker. BMJ. 1978;1(6120):1109-10.

29. Lane JCE, Weaver J, Kostka K, Duarte-Salles T, Abrahao MTF, Alghoul $\mathrm{H}$, et al. Risk of hydroxychloroquine alone and in combination with azithromycin in the treatment of rheumatoid arthritis: a multinational, retrospective study. Lancet Rheumatol. 2020;2(11):e698-e711.

30. Liu D, Li X, Zhang Y, Kwong JS-W, Li L, Zhang Y, et al. Chloroquine and hydroxychloroquine are associated with reduced cardiovascular risk: a systematic review and meta-analysis. Drug Des Devel Ther. 2018;12:1685-95.

31. Morris SJ, Wasko MCM, Antohe JL, Sartorius JA, Kirchner HL, Dancea S, et al. Hydroxychloroquine use associated with improvement in lipid profiles in rheumatoid arthritis patients. Arthritis Care Res. 2011;63(4):530-4.

32. Jung H, Bobba R, Su J, Shariati-Sarabi Z, Gladman DD, Urowitz M, et al. The protective effect of antimalarial drugs on thrombovascular events in systemic lupus erythematosus. Arthritis Rheum. 2010;62(3):863-8.

33. Faselis C, Zeng-Treitler Q, Cheng Y, Kerr GS, Nashel DJ, Liappis AP, et al. Cardiovascular safety of hydroxychloroquine in veterans with rheumatoid arthritis. Arthritis Rheum. 2021;73:1589-600.

\section{Publisher's Note}

Springer Nature remains neutral with regard to jurisdictional claims in published maps and institutional affiliations.

Ready to submit your research? Choose BMC and benefit from

- fast, convenient online submission

- thorough peer review by experienced researchers in your field

- rapid publication on acceptance

- support for research data, including large and complex data types

- gold Open Access which fosters wider collaboration and increased citations

- maximum visibility for your research: over $100 \mathrm{M}$ website views per year

At BMC, research is always in progress.

Learn more biomedcentral.com/submissions 